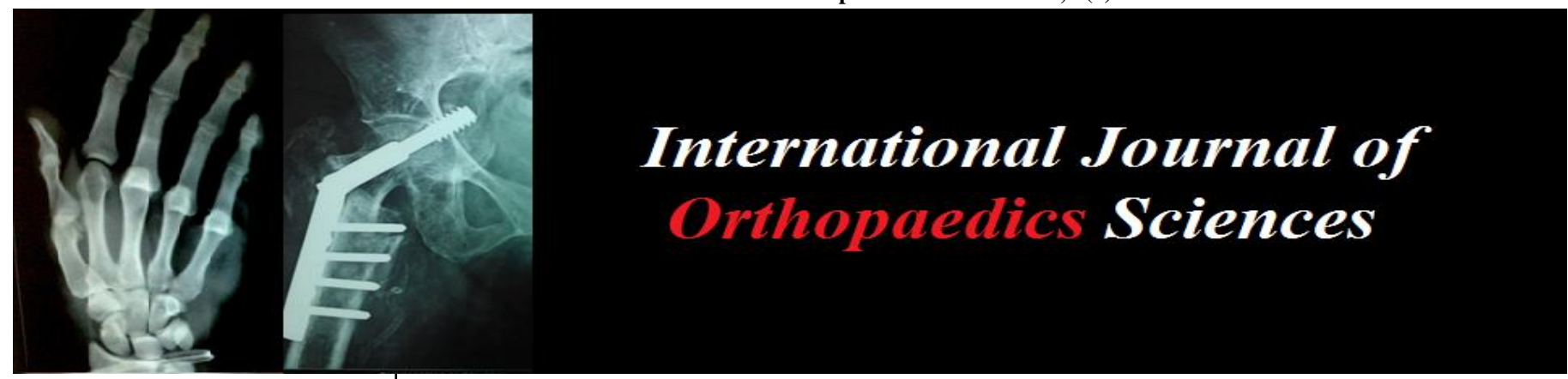

ISSN: $2395-1958$

IJOS 2018; 4(3): 326-328

(C) 2018 IJOS

www.orthopaper.com

Received: 29-05-2018

Accepted: 30-06-2018

Dr. Swagat Mahapatra

Assistant Professor,

Department of Orthopaedics,

Dr. RML Institute of Medical

Sciences, Lucknow,

Uttar Pradesh, India

Dr. Sachin Awasthi

Associate Professor,

Department of Orthopaedics,

Dr. RML Institute of Medical

Sciences, Lucknow,

Uttar Pradesh, India

Dr. Pankaj Aggarwal

Assistant Professor,

Department of Orthopaedics,

Dr. RML Institute of Medical

Sciences, Lucknow,

Uttar Pradesh, India

Dr. Siddharth Tiwari

Senior Resident,

Department of Orthopaedics,

Dr. RML Institute of Medical

Sciences, Lucknow,

Uttar Pradesh, India

Dr. Chandrasekhar Verma

Senior Resident,

Department of Orthopaedics,

Dr. RML Institute of Medical

Sciences, Lucknow,

Uttar Pradesh, India

Correspondence

Dr. Sachin Awasthi

Associate Professor,

Department of Orthopaedics,

Dr. RML Institute of Medical

Sciences, Lucknow,

Uttar Pradesh, India

\section{Functional outcome following open carpal tunnel release}

\author{
Dr. Swagat Mahapatra, Dr. Sachin Awasthi, Dr. Pankaj Aggarwal, \\ Dr. Siddharth Tiwari and Dr. Chandrasekhar Verma
}

DOI: https://doi.org/10.22271/ortho.2018.v4.i3f.59

\section{Abstract}

Introduction: Carpal tunnel syndrome is the most commonly reported upper limb neuropathy, and occurs due to median nerve entrapment in the carpal tunnel of the wrist. Open carpal tunnel release is the most accepted treatment modality and offers good results. The present study was conducted with the aim to determine the functional outcome following open carpal tunnel release.

Materials and methods: This is an institutional based prospective interventional study conducted at Dr RML Institute of Medical Sciences, Lucknow. 100 patients with Carpal Tunnel syndrome, fulfilling the inclusion criteria, were treated with open carpal tunnel release. Diagnosis of carpal tunnel syndrome was based upon clinical features and physical examination. Preoperative radiographs, nerve conduction velocity and relevant blood investigations were performed. Patients were followed up postoperatively at 6 weeks, 3 months and 6 months. Relevant statistical analysis of the data was done.

Results: The study had 100 subjects with the mean age of $42.82 \pm 14.68$ years. $52 \%$ in our group were females and $48 \%$ males. Bilateral hand involved was seen in $82 \%$ of cases and $18 \%$ were unilateral. Dominant hand involvement was seen in $36 \%$ of cases, non dominant involvement in $40 \%$ of cases and both hand equally involved in $24 \%$ of cases. $32 \%$ of patients had associated hypothyroidism and $22 \%$ had associated Rheumatoid arthritis. Preoperative and 6 months postoperative Quick-Dash scores revealed significant improvement.

Conclusion: Outcomes following open Carpal Tunnel release are very encouraging in terms of functional results as well as patient satisfaction. Quick dash score can be considered as a reliable and valuable tool for evaluating the outcome following surgery in the upper extremity. All the subjects showed a considerable improvement in the score after our procedure.

Keywords: Carpal tunnel, transverse carpal ligament, quick dash

\section{Introduction}

Carpal tunnel syndrome is the most common upper limb neuropathy and occurs due to median nerve entrapment in the carpal tunnel of the wrist. First description of the condition was done by Paget in $1854^{[1]}$. Most commonly associated symptoms of this condition include paresthesia, pain and numbness in the areas of distribution of median nerve distribution. Females are more commonly affected than males. Various conditions can cause compression of the median nerve at the wrist and can lead to its ischemia ${ }^{[2]}$. The signs and symptoms are dependent upon the severity of the condition. The initial features are due to involvement of the sensory component of the nerve and the later complaints are due to involvement of the motor component. The most prominent symptom Subjects are usually awakened during the middle of night by the severe pain and they hang their hand out of their bed and shake it energetically to relieve pain. Both surgical and non surgical treatment modalities are available. But there is little information on benefits of non surgical treatment modality ${ }^{[3]}$. Surgery has shown long term benefits in management. Decompression of the nerve is the commonly performed procedure. Open carpal tunnel release is the most accepted treatment modality and offers good results ${ }^{[4]}$. The present study was conducted with the aim to determine the functional outcome after open carpal tunnel release.

\section{Materials and methods}

The study was conducted at Ram Manohar Lohiya Institute of Medical Sciences, Lucknow, an 1100 bedded quaternary care super-specialty teaching hospital. 
We reviewed 100 patients who underwent open carpal tunnel release in the hospital during a period of 1 year from January 2017 to January 2018. We collected information as to the age and sex distribution, most common symptoms, associated comorbidities, occupation, etc. The data were collected from charts, physical assessment slips, and discharge summaries. After adequate Institutional review board clearance and adequate consent patients were enrolled for our study. Diagnosis of carpal tunnel syndrome was based upon clinical features and physical examination. Preoperative radiographs of the wrist, nerve conduction velocity of both hand median nerves, serum tests for level of thyroid and inflammatory markers were performed. All the subjects with confirmed diagnosis of carpal tunnel syndrome were included in the study. Subjects with previous carpal tunnel release, history of nerve compressions, connective tissue disease and peripheral vascular diseases were excluded from the study. Pregnant patients with symptoms of median nerve compression were also excluded from the study. After the preoperative evaluation all the subjects underwent open carpal tunnel release and median nerve neurolysis under local anesthesia. Subjects were discharged on the same day. Carpal tunnel splint was applied post operatively for 2 weeks. Patients were followed up postoperatively at 6 weeks, 3 months and 6 months. All the subjects were made to fill the quick dash assessment form preoperatively and at every follow up visit. Data was entered into excel sheets, and statistical analysis of the data was done using SPSS version 21 software. Continuous data were reported as mean \pm standard deviation. Categorical data were reported as numbers and percentages and were analyzed using Chi-square test or Fisher's exact test as appropriate. The value $P<0.05$ was considered statistically significant.

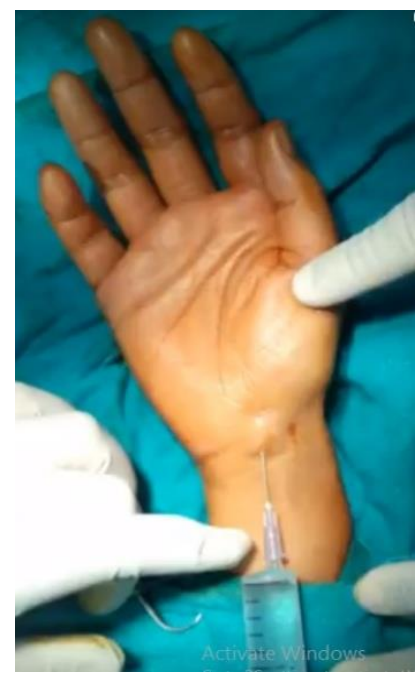

Fig 1: Administeration of Local Anesthesia

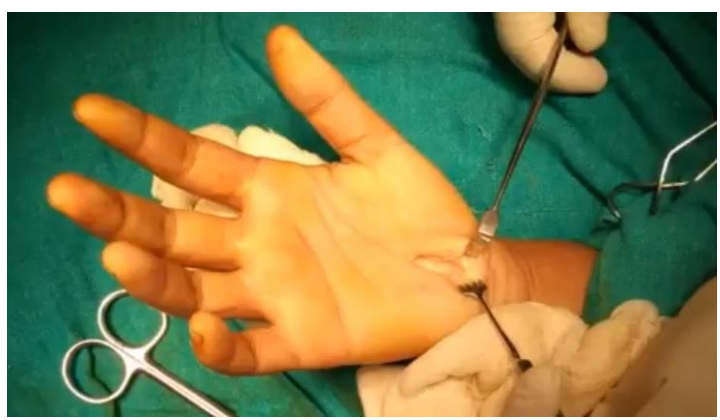

Fig 2: Open Release of Carpal Tunnel

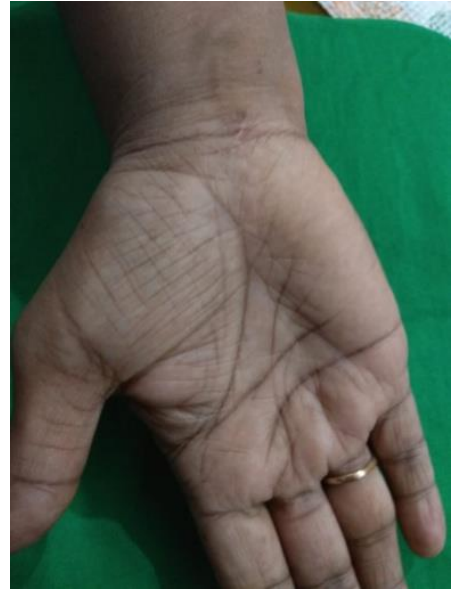

Fig 3: Post Operative scar mark

\section{Results}

The present study consisted of 100 subjects with the mean age of $42.82 \pm 14.68$ years (Table 1 ). The youngest patient was 18 years old and the oldest was 68 years old. There were majority of females in the study group. $52 \%$ in our group were females and $48 \%$ males (Table 2). Bilateral hand involved was seen in $82 \%$ of cases and $18 \%$ were unilateral (Table 3). However in bilateral cases the more symptomatic hand was taken into consideration for observations. Dominant hand involvement was seen in $36 \%$ of cases, non dominant involvement in $40 \%$ of cases and both hand equally involved in $24 \%$ of cases (Table 4 ). $32 \%$ of patients had associated hypothyroidism and $22 \%$ had associated Rheumatoid arthritis (Tables $5 \& 6$ ). Comparison of preoperative and 6 months postoperative Quick-Dash scores revealed significant improvement with $\mathrm{p}$ value less than 0.00001 (Table 7).

Table 1: Age Incidence

\begin{tabular}{|c|c|}
\hline Age in years & No. of cases \\
\hline $11-20$ & 1 \\
\hline $21-30$ & 14 \\
\hline $31-40$ & 24 \\
\hline $41-50$ & 19 \\
\hline $51-60$ & 25 \\
\hline $61-70$ & 17 \\
\hline
\end{tabular}

Mean age $-42.82 \pm 14.68$ years

Table 2: Sex Distribution

\begin{tabular}{|c|c|c|}
\hline & No of Cases & Percentage (\%) \\
\hline Male & 48 & $48 \%$ \\
\hline Female & 52 & $52 \%$ \\
\hline Total & 100 & $100 \%$ \\
\hline
\end{tabular}

Table 3: Incidence of Bilateral Hand Involvement

\begin{tabular}{|c|c|c|}
\hline Hand Involvement & No Of Cases & Percentage (\%) \\
\hline Single Hand & 18 & $18 \%$ \\
\hline Both Hands & 82 & $82 \%$ \\
\hline Total & 100 & $100 \%$ \\
\hline
\end{tabular}

Table 4: Incidence of Dominant Hand Involvement

\begin{tabular}{|c|c|c|}
\hline & No of Cases & Percentage (\%) \\
\hline Dominant & 36 & $36 \%$ \\
\hline Non Dominant & 40 & $40 \%$ \\
\hline Equally Affected & 24 & $24 \%$ \\
\hline Total & 100 & 100 \\
\hline
\end{tabular}


Table 5: Association with Hypothyroidism

\begin{tabular}{|c|c|c|}
\hline & No of Cases & Percentage (\%) \\
\hline Hypothyroid & 36 & $36 \%$ \\
\hline Normal Thyroid & 64 & $100 \%$ \\
\hline Total & 100 & $100 \%$ \\
\hline
\end{tabular}

Table 6: Association with Rheumatoid Arthritis

\begin{tabular}{|c|c|c|}
\hline & No of Cases & Percentage (\%) \\
\hline Rhematoid +VE & 22 & $22 \%$ \\
\hline Rheumatoid -VE & 78 & $78 \%$ \\
\hline Total & 100 & $100 \%$ \\
\hline
\end{tabular}

Table 7: Quick Dash Scores at Long Term Follow Up

\begin{tabular}{|c|c|c|}
\hline Quickdash Score & No. of Patients-Pre Op & No. of Patients-Post Op \\
\hline $0-25$ & 12 & 62 \\
\hline $26-50$ & 26 & 25 \\
\hline $51-75$ & 39 & 9 \\
\hline $76-100$ & 23 & 4 \\
\hline TOTAL & 100 & 100 \\
\hline
\end{tabular}

The chi-square statistic is 65.9238 . The $\mathrm{p}$-value is $<0.00001$. The result is significant at $p<0.01$

\section{Discussion}

Carpal Tunnel Syndrome is the most common type of compression neuropathy that constitutes for about $90 \%$ of entrapment neuropathies ${ }^{[5,6]}$. Carpal tunnel syndrome is a symptomatic compression of the median nerve at the area of wrist and is characterized physiologically by proof of increase in pressure within the carpal tunnel and decreased function of the median nerve ${ }^{[7]}$. Our study measures the functional recovery of patients following open carpal tunnel release. The age group of study subjects in our series was varied with ages ranging from 18 years old to the eldest being 68 years old. Maximum numbers of patients were found in the fourth and $6^{\text {th }}$ decades. Studies by De Krom et al and by Nordstrom et al have stated that the most common age of development for carpal tunnel syndrome is $45-60$ years with only $10 \%$ of subjects younger than 31 years ${ }^{[8,9]}$. Female preponderance in our study was similar to most studies by Mondelli et al. ${ }^{[10]}$ and Palmer et al. ${ }^{[11]}$ where the females population in the series was 72 and 83 percent respectively. As per our data dominance of hand and its relation to symptoms could not be correlated. Most industrial workers had dominant hand involvement whereas as patients having systemic disorders like thyroid and rheumatoid had bilateral involvement. Dominant hand involvement in Industrial workers has been shown by Lam et al. ${ }^{[12]}$ Association of hypothyroidism and Rheumatoid arthritis with carpal tunnel syndrome has been demonstrated in our data. These causes of carpal tunnel syndrome have been well demonstrated earlier by numerous authors including Boz et al. ${ }^{[10]}$ Mondelli et al. ${ }^{[13]}$ and many others. Quick DASH scores as a functional parameter in patients with Carpal tunnel syndrome has not been used till date. The significant improvement of these scores following surgery proves that Open carpal tunnel release is a very good and reproducible method for treatment of carpal tunnel syndrome.

\section{Conclusion}

Surgical management of carpal Tunnel syndrome with open carpal tunnel release is an effective and safe procedure. Quick dash score can be considered as a reliable and valuable tool for evaluating the outcome of this surgical release. It is technically non-demanding, results in patient satisfaction and can be performed safely by Orthopaedic surgeons with experience.

\section{References}

1. Ibrahim I, Khan WS, Goddard N, Smitham P. Carpal tunnel syndrome: A review of the recent literature. Open Orthop J. 6:69-76.

2. Alfonso C, Jann S, Massa R, Torreggiani A. Diagnosis, treatment and follow-up of the carpal tunnel syndrome: A review. Neurolog Sci. 2010; 31:243-52.

3. O'Connor D, Marshall S, Massy-Westropp N. Nonsurgical treatment (other than steroid injection) for carpal tunnel syndrome. Cochrane Database Syst Rev. 2003; (1):CD003219.

4. Turner A, Kimble F, Gulyas K, Ball J. Can the outcome of open carpal tunnel release be predicted?: A review of the literature. ANZ J Surg 2010; 80:50-4.

5. Ibrahim I, Khan WS, Goddard N, Smitham P. Carpal tunnel syndrome: a review of the recent literature. Open Orthop J. 2012; 6:69-76.

6. Mashoof AA, Levy HJ, Soifer TB, Miller-Soifer F, Bryk E, Vigorita V. Neural anatomy of the transverse carpal ligament. Clin Orthop Relat Res. 2001; 386:218-21.

7. American Academy of Orthopaedic Surgeons Work Group Panel. Clinical guidelines on diagnosis of carpal tunnel syndrome.

8. De Krom MC, Kester AD, Knipschild PG, Spaans F. Risk factors for carpal tunnel syndrome. Epidemiology. 1990; 132(6):1102-10.

9. Nordstrom DL, DeStefano F, Vierkant RA, Layde PM. Incidence of diagnosed carpal tunnel syndrome in a general population. Epidemiology. 1998; 9(3):342-5.

10. Mondelli M, Giannini F, Giacchi M. Carpal tunnel syndrome incidence in a general population. Neurology. 2002; 58(2):289-94.

11. Palmer KT, Harris EC, Coggon D. Carpal tunnel syndrome and its relation to occupation: a systematic literature review. Occup Med (Lond). 2007; 57(1):57-66.

12. Lam N, Thurston A. Association of obesity, gender, age and occupation with carpal tunnel syndrome. Aust N Z J Surg. 1998; 68(3):190-3.

13. Boz C, Ozmenoglu M, Altunayoglu V, Velioglu S, Alioglu Z. Individual risk factors for carpal tunnel syndrome: an evaluation of body mass index, wrist index and hand anthropometric measurements. Clin Neurol Neurosurg. 2004; 106(4):294-9. 